\title{
A escola específica ou a regular?
}

\section{The specific school or the regular school?}

DOI: $10.46814 / \operatorname{lajdv3n4-057}$

Recebimento dos originais: 01/05/2021

Aceitação para publicação: 30/06/2021

Khatlen Evelyn Queiroz Oliveira

Faculdade Martha Falcão-FMF

\author{
Denilson Diniz Pereira \\ Universidade Federal do Amazonas-UFAM
}

\section{RESUMO}

Estamos em um momento social e político onde a pauta inclusão escolar de alunos com necessidades educacionais especiais na rede regular de ensino esta sendo debatido de forma ativa, devendo a mesma ser uma ação prática e um direito garantido. A lei é clara quanto à obrigatoriedade da matrícula independente de sua deficiência e a garantia de sala de recurso multifuncional (SRM) para o desenvolvimento do atendimento educacional especializado (AEE), garantindo currículo, método, técnicas, recursos educacionais e organização específica para as pessoas com deficiência. Devido às políticas publicas alguns pais ficam receosos em matricular seus filhos em uma escola regular ou específica, pois, em sua maioria as escolas amazônicas não possuem condições efetivas de aprendizagem e desenvolvimento para as pessoas com deficiência. Nesta perspectiva, conduzimos o leitor a refletir qual seria a escola adequada para a inserção de alunos com deficiência? De forma a torná-lo independente e participante de um grupo social que possa assim desenvolver suas habilidades no processo de ensino-aprendizagem.

Palavras-chave: Educação Especial, Políticas Públicas, Família e Ensino Regular.

\begin{abstract}
We are in a social and political moment where the issue of school inclusion for students with special educational needs in the regular education system is being actively discussed, and it should be a practical action and a guaranteed right. The law is clear as to the mandatory enrollment regardless of disability and the guarantee of a multipurpose resource room (SRM) for the development of specialized educational services (AEE), ensuring curriculum, method, techniques, educational resources and specific organization for people with disabilities. Due to public policies, some parents are afraid to enroll their children in a regular or specific school, because, most of the Amazon schools do not have effective learning and development conditions for people with disabilities. From this perspective, we lead the reader to reflect on what would be the appropriate school for the insertion of students with disabilities? In order to make them independent and participate in a social group that can thus develop their abilities in the teaching-learning process.
\end{abstract}

Keywords: Special Education, Public Policies, Family and Regular Education. 


\section{INTRODUÇÃO}

Esta pesquisa foi desenvolvida a partir de pesquisa bibliográfica em livros, periódicos, teses e indexadores em bases de dados, tendo como objetivo proporcionar aos leitores uma reflexão sobre as escolas específicas e regulares a partir da inclusão de alunos com necessidades educacionais especiais, proporcionando a reflexão sobre o dual educação especial e políticas pública para a educação especial.

O atendimento ás necessidades educacionais especiais é alvo de discussões entre os grandes centros de pesquisas a partir dos diferentes segmentos educacionais e sociais. No entanto, inserir alunos com deficiência no ensino regular é um grande desafio, pois atual Política Nacional de Educação Especial na Perspectiva da Educação Inclusiva. aponta para uma definição de prioridade e define como aluno com necessidades educacionais especiais aquele que apresenta necessidades específicas de aprendizagem curriculares diferenciadas dos demais alunos e que requeiram recursos pedagógicos e metodologias específicas. (BRASIL, 2018)

Por outro lado, é importante ressaltar que não é suficiente apenas esse acolhimento nas escolas regulares, mas que o aluno com necessidades educacionais especiais tenha condições efetivas de aprendizagem e desenvolvimento de suas capacidades, sendo necessário reestruturações nas escolas para assegurar esses alunos com suportes adequados e específicos com práticas pedagógicas visto que a Educação Especial baseia-se numa educação de qualidade para todos e no respeito a diversidade.

Esta pesquisa estrutura-se nas seguintes problemáticas: a aceitação da família, o nível de dificuldade que o professor encontra para ensinar alunos com necessidades educacionais especiais em escolar regular, à seleção dos alunos com necessidades especiais para uma escola regular e a escola específica x escola regular.

O objetivo da pesquisa foi conduzir a reflexão sociocultural sobre a problemática que envolve a inclusão de alunos com necessidades educacionais especiais nas escolas regulares de ensino, de forma a analisar a importância de uma Escola Específica, avaliando assim o desenvolvimento cognitivo dos alunos com deficiência.

\section{METODOLOGIA:}

Para o desenvolvimento da pesquisa no primeiro momento realizou-se um levantamento bibliográfico relacionado à temática proposta. Assim "a pesquisa bibliográfica foi desenvolvida com base em material já elaborado, constituída principalmente de livros e artigos científicos. [...]" (GIL, 2008, p. 50). Para posterior prosseguimento ao estudo investigativo de campo.

Posteriormente a presente pesquisa foi realizada conforme a metodologia qualitativa favorecendo a melhor abrangência da realidade dos fenômenos. Nessa perspectiva Bogdan e Biklen (1994, p. 49) mencionam: 
A abordagem da investigaç̃̃o qualitativa exige que o mur que nada é trivial, que tudo tem potencial para constituir uma pista que nos permita estabelecer uma compreensão mais esclarecedora do nosso objeto de estudo. [...] Nada é considerado como um dado adquirido e nada escapa à avaliação. A descrição funciona bem como método de recolha de dados, quando se pretende que nenhum detalhe escape ao escrutínio.

Nesse sentido, a pesquisa qualitativa facilitou a descrição dos problemas detectados, pois permitiu uma melhor interpretação das particularidades e atitudes dos indivíduos que serão pesquisados. Pois para Pimenta (2011) se estudamos as pessoas qualitativamente, passamos a conhecêlas e experimentamos o que elas sentem em suas lutas cotidianas na sociedade.

A concepção que norteou as reflexões teóricas foi a fenomenologia por permitiu ao pesquisador uma maior liberdade para interpretar o seu objeto de estudo considerando a subjetividade, possibilitando a busca da essência e a exposição dos fatos como realmente são.

Pois, segundo Fazenda (2001, p. 63):

\begin{abstract}
A Pesquisa Fenomenológica, [...] parte da compreensão de nosso viver - não de definições ou conceitos - da compreensão que orienta a atenção para aquilo que vai se investigar. Ao percebermos novas características do fenômeno, ou ao encontrarmos no outro interpretações, ou compreensões diferentes, surge para nós uma nova interpretação que levará a outra compreensão.
\end{abstract}

Nesse sentido a pesquisa fenomenológica deixa em aberto interpretações, a fim de discorrer outras elucidações a cerca do que se investiga, visto que no mundo não há nada pronto. Dessa forma, parafraseando Fazenda (2001) o inacabamento do ponto de vista dos fenomenólogos não significa fracasso ou indefinição, mas sim uma forma da fenomenologia mostrar-se em sua verdadeira tarefa e produtividade de novas interpretações.

Nessa perspectiva foi realizada uma pesquisa de Campo, para a qual foi feita um breve estudo bibliográfico com a finalidade de conhecer os trabalhos que já foram realizados a cerca da temática e as possíveis problemáticas que a pesquisa abordou. Vale ressaltar que a pesquisa de Campo possibilita a proximidade do investigador com o objeto da pesquisa, e segundo Marconi e Lakatos (2009, p. 188) favorece ao pesquisador "conseguir informações e/ou conhecimentos acerca de um problema, para o qual se procura uma resposta”.

Nesse contexto Gil (2007, p.53) enfatiza que:

No estudo de campo, o pesquisador realiza a maior parte do trabalho pessoalmente, pois é enfatizada a importância de o pesquisador ter tido ele mesmo uma experiência direta com a situação de estudo. Também se exige do pesquisador que permaneça o maior tempo possível na comunidade, pois somente com essa imersão na realidade é que se podem entender as regras, os costumes e as convenções que regem o grupo estudado. 
Foi assumido, à elaboração desta pesquisa, o compromisso de manter uma postura ética com relação ao material coletado a partir de observações, questionários e entrevistas, a fim de ter o cuidado de não revelar informações que possam constranger de qualquer forma os sujeitos entrevistados.

\title{
3 RESULTADOS E DISCUSSÃO:
}

Neste momento, será exposto à análise realizadas durante a pesquisa, com as articulações com os autores que embasaram este trabalho.

\section{A ACEITAÇÃO DA FAMÍLIA:}

Sabemos o quão é difícil para a família aceitar seu filho deficiente, de forma metafórica podemos comparar a uma viagem que você tanto planeja e acaba não sendo concretizada por alguma fatalidade, frustrando os planos de vida.

Buscaglia apud Cortez e Regen, (1996, p. 125).

\begin{abstract}
A realidade é que o problema foi trazido para a família pela criança deficiente e, portanto é normal que a família sinta um certo ressentimento pela deficiência, mas é também verdade que a criança portadora de deficiência é apenas mais um membro da família e, é antes de tudo uma criança... caso essa diferenciação não seja feita, o ressentimento que a família sente em relação à deficiência pode inconscientemente transformar-se em rejeição pela criança.
\end{abstract}

Com isso acaba prejudicando o desenvolvimento da criança nas escolas ditas regulares, pois sabemos que a família é a principal responsável pelas ações do seu filho com necessidades educacionais especiais. É ela que lhe oferece a primeira formação, o aluno que tem a orientação profissional e da família poderá adquirir competência profissional e pessoal.

No entanto para Aranha (2004, p.29):

\begin{abstract}
Sabe-se, entretanto, que a família tem se encontrado, historicamente, numa posição de dependência de profissionais em diferentes áreas do conhecimento, no sentido de receberem orientações de como proceder em relação ás necessidades especiais dos seus filhos
\end{abstract}

Quando a família aceita a deficiência de seu filho busca o dialogo e esclarecimentos com uma equipe multidisciplinar, estabelecendo uma relação entre a família e profissionais nas decisões do que é melhor para seus filhos.

As pessoas com necessidades educacionais especiais, relaciona-se aos alunos que apresentam elevada capacidade ou dificuldades de aprendizagem. Esses alunos não são, necessariamente deficientes, mas são especiais porque exigem respostas específicas adequadas. Assim, cabe ressaltar que não há diferença entre os termos, sendo que ambos se referem às pessoas que tem algum tipo de deficiência. 
É necessário que a família construa conhecimentos sobre as necessidades especiais de seus filhos, bem como no desenvolvimento psicossocial, para que proporcione o bem estar e uma vida de qualidade.

\title{
5 A SELEÇÃO DOS ALUNOS COM NECESSIDADES EDUCACIONAIS ESPECIAIS PARA UMA ESCOLA REGULAR
}

$\mathrm{O}$ acesso de alunos com necessidades educacionais especiais de qualquer ordem, cujas necessidades decorrem de sua elevada capacidade ou de suas dificuldades nas escolas ditas regulares, nada mais é do que um grande desafio, pois não basta só incluir ou simplesmente matricular esse aluno, e sim dá o devido suporte para que os mesmos possam desenvolver as suas habilidades dentro da sua capacidade de aprender.

A seleção desses alunos com necessidades educacionais especiais nas escolas regulares acontece da seguinte maneira: os pais o matriculam com a documentação necessária (certidão de nascimento, cartão de vacina, comprovante de resistência e dois números de telefone); e no preenchimento da ficha pergunta-se o aluno possui alguma deficiência, se houver apresenta-se o laudo especificando qual é o nível de necessidade especial, mas vale ressaltar que nem todos têm esse laudo, porém são matriculados assim mesmo.

\begin{abstract}
A Resolução CNE/CEB número 2, de 11 de setembro de 2001, institui Diretrizes Nacionais para a Educação Especial na Educação Básica, que determina que os sistemas de ensino devem matricular todos os alunos e que é função da escola organizar-se para os atendimentos dos educandos com necessidades educacionais especiais, bem como criar e fazer funcionar um setor responsável pela Educação Especial, dotado de recursos humanos, materiais e financeiros que sustentem o processo de educação inclusiva.
\end{abstract}

Visto que a inclusão sem laudo é um direito do aluno e de posse de toda a documentação, é montado o plano de atendimento no AEE, com base nas necessidades do aluno.

\section{NÍVEL DE DIFICULDADE QUE O PROFESSOR ENCONTRA PARA ENSINAR ALUNOS COM NECESSIDADES EDUCACIONAIS ESPECIAIS EM ESCOLA REGULAR}

O professor tem o papel fundamental no processo de aprendizagem dos alunos e por meio de sua prática pedagógica, pode-se observar alteração fora do comportamento esperado de seus alunos.

Parker (1996 apud ROHDE et alii, 2003) considera que:

Os professores são, com frequência, aqueles que mais facilmente percebem quando um aluno está tendo problemas de atenção, aprendizagem, comportamento ou emocionais/efetivos e sociais. (p.205) 
Quando o professor recebe uma criança com necessidades educacionais especiais ele se vê no meio de um grande desafio, onde precisa dar um novo formato a sua aula, tornando-as dinâmicas e objetivas, com atividades que sejam motivadoras e que as instruções dadas sejam claras e gradativas acompanhando o ritmo e interesse dos alunos com necessidades educacionais especiais.

Mas sabemos que com toda formação continuada, as informaçõessobre as necessidades educacionais especiaisos professores ainda se sentem despreparados em ter um aluno com algum transtorno em sala de aula. Pois eles alegam que as salas são superlotadas, número elevado de alunos por turma, estrutura física inadequada e não tem prática pedagógica em relação às crianças que necessitam de necessidades educacionais específica.

Portanto, os professores necessitam de formação continuada sobre as necessidades educacionais especiais e sobre como se dá o desenvolvimento cognitivo das pessoas em seu processo de aquisição de conhecimentos. Não são necessários novos professores, especializados, é necessário que os professores atuais estejam abertos ás mudanças desse novo contexto e que possam refletir e repensar suas concepções e conhecimentos antigos e novos, seu papel e posicionamento diante de uma nova prática pedagógica.

\section{A ESCOLA REGULAR X ESCOLA ESPECÍFICA}

Na educação especial, uma escola deve se preparar para enfrentar o desafio de oferecer uma educação com qualidade para todos seus alunos. Considerando que, cada aluno numa escola apresenta características próprias e um conjunto de valores e informações que os tornam únicos e especiais, constituindo uma diversidade de interesses e ritmos de aprendizagem, o desafio da escola hoje é trabalhar com essa diversidade, na tentativa de construir um novo conceito do processo ensino e aprendizagem de modo que sejam incluídos neste processo todos que deles, por direitos, são sujeitos.Com isso, a escolas têm um papel fundamental na sociedade, pois busca promover a função e socialização dos sujeitos, é o espaço no qual se deve favorecer a os indivíduos o acesso ao conhecimento e o desenvolvimento de competências e habilidades. Para que objetivo seja alcançado. A escola precisa ser organizada de forma a garantir à prática pedagógica no processo de aprendizagem de cada aluno.

A LDB (Lei de Diretrizes e Bases da Educação Nacional), lei n 9.394 de 20 de dezembro de 1996, capitulo V, trata e específica o direito do aluno com necessidades educacionais especiais e o dever da instituição escolar em assegurar a adequação no processo de ensino.

No entanto, a lei define a Educação Especial com uma modalidade de educação escolar, e que deve ser oferecida na rede regular de ensino, dando o direito ao aluno com necessidade especial de ter 
um atendimento especializado, quando necessário. A mesma dedica um capítulo à educação especial e abrange todos os níveis de ensino desde a Educação Infantil ao Ensino Superior (Brasil, 1996)

LDBE - Lei n 9.394 de 20 de Dezembro de 1996 em seu artigo 59.

\begin{abstract}
Art. 59. Os sistemas de ensino assegurarão aos educandos com deficiência, transtornos globais do desenvolvimento e altas habilidades ou superdotação: (Redação dada pela Lei ${ }^{\circ} 12.796$. de $\underline{2013)}$

I - currículos, métodos, técnicas, recursos educacionais e organização específica, para atender as suas necessidades;

II - terminalidade específica para aqueles que não puderam atingir o nível exigido pra conclusão do ensino fundamental, em virtude de suas deficiências, a aceleração para concluir em menor tempo o programa escolar para os superdotados;

III - professores com especialização adequada em nível médio ou superior, para atendimento especializado, bem como professores do ensino regular capacitados para a integração desses educandos nas classes comuns;

IV - educação especial para o trabalho, visando a sua efetiva integração na vida em sociedade, inclusive condições adequadas para os que não revelarem capacidade de inserção no trabalho competitivo, mediante articulação com órgãos oficiais afins, bem como para aqueles que apresentam uma habilidade superior nas áreas artísticas, intelectual ou psicomotora;

V -acesso igualitário aos benefícios dos programas sociais suplementares disponíveis para o respectivo nível do ensino regular.
\end{abstract}

Não basta a garantia da lei. Com certeza, a lei é sim, uma forma de começarmos as mudanças. Mas, a inclusão deve ir além das leis e dos espaços definidos como regular ou específica. Pois os pais encontram um grande dilema em matricular seus filhos numa escola regular ou especifica. Pois segundo a Resolução n.2/2001, em seu artigo $2^{\circ}$ :

Os sistemas de ensino devem matricular todos os alunos, cabendo ás escolas organizar-se para o atendimento aos educandos com necessidades educacionais especiais, assegurando as condições necessárias para a educação de qualidade para todos.

Fazendo uma pesquisa, sabemos que as escolas regulares não têm uma estrutura propriamente dita da escola específica, pois se tratando de inclusão de alunos com necessidades educacionais especiais, devemos incluir esse aluno por inteiro e não pela metade e acima de tudo nem sempre esse aluno especial tem acompanhamento necessário, as vezes é apenas ouvinte em sala de aula, pois alguns professores não tem formação continuada e nem sabe lhe dá com alunos com limitações físicas, motoras, sensoriais, cognitiva, síndrome ou transtornos diversos.

No entanto, para se trabalhar com alunos com necessidades educacionais especiais citada acima, devemos ter toda uma equipe profissional para desenvolver e estimular a cognição desses alunos especiais; implica também na criação e adequação de estruturas físicas que facilitem o ingresso e a movimentação de todas as pessoas.É importante também, que se tenha preocupação e cuidado com a linguagem que se utiliza, para não haver voluntariamente ou involuntariamente o preconceito e discriminação em relação ás pessoas ou grupos, conforme suas características, ressaltando ainda, que 
antes de iniciar um trabalho com alunos com necessidades educacionais especiais, é necessário que se faça um preparo dos demais alunos, no sentido de sensibilizar a importância da convivência na diversidade e no respeito ás diferenças.

Não estamos aqui para defender qual a melhor escola e sim verificar o que é melhor para cada aluno com necessidades educacionais especiais, pois nem toda escola dita regular tem uma estrutura física para receber esses alunos e tampouco professores que saibam lhe dá com essas diferenças. É importante para cada indivíduo, em cada época específica de sua vida, respeitando seus momentos, suas capacidades e necessidades, aceitar e valorizar as diferenças e a diversidade é o primeiro passo para se fazer parte de um processo verdadeiramente inclusivo, e para a criação de uma escola de qualidade para todos.

\section{CONCLUSAO PARCIAL:}

Todo indivíduo tem direito a uma educação de qualidade, pois é o alicerce para o desenvolvimento de qualquer cidadão. E se falando de educação para todos, as pessoas com necessidades educacionais especiais tem todo o direito de inclusão e não só de integração. Pois sabemos o que existe de fato é uma integração para as pessoas com necessidades especiais, pois quando se fala de inclusão, estamos falando de acolher todas as pessoas, sem exceção, no sistema de ensino, independentemente de cor, classe social e condições físicas e psicológicas. Isso assegurar a todos a igualdade de condições para o acesso e a permanência na escola

É na sua rotina escolar que os alunos desenvolvem suas habilidades cognitiva, têm acesso aos diferentes conteúdos curriculares. Por isso precisamos de profissionais capacitados, professores que estejam abertos as mudanças, de apoio pedagógico e recursos didáticos, para que o objetivo seja alcançado.

Assim, uma escola somente poderá ser considerada inclusiva quando estiver organizada para favorecer a cada aluno, independentemente de qualquer necessidade educacional especial ensino significativo que garanta o acesso ao conjunto sistematizado de conhecimentos que resulte em uma contribuição para o processo de aprendizagem de cadaaluno. 


\section{REFERENCIAS}

Brasil (1996). Lei 9.394/96. Lei de Diretrizes e Bases da Educação Nacional.Ministério da Educação: Diretrizes Nacionais para a Educação Especial naEducação Básica. MEC/SEESP, 2001.

BRASIL. Ministério Público Federal. $\mathrm{O}$ acesso de alunos com deficiência às escolas e classes comuns da rede regular. 2ed. Brasília: Procuradoria Federal dos Direitos doCidadão, 2004.

BUENO, J. G. S. Educação Especial Brasileira: integração/segregação do aluno diferente. 2 ed. São Paulo: EDUC, 1999.

A educação inclusiva e as novas exigências para a formação de professores: algumas considerações. In: BICUDO, M. A.; SILVA, J. C. A. org. Formaçãodo educador e avaliação educacional: formação inicial e contínua. São Paulo: Editora UNESP, 1999b. p. 149-164.

BRASIL, Ministério da Educação, Secretaria de Educação Especial. Projeto Escola

Viva: Garantindo o acesso e permanência de todos os alunos na escola -Alunos com necessidades educacionais especiais, Brasília: MEC/SEESP, 2000, vol. 6.

BRASIL, Ministério da Educação, Secretaria de Educação Especial. Projeto Escola

Viva: Garantindo o acesso e permanência de todos os alunos na escola: Alunos com necessidades educacionais especiais - Adaptações Curriculares de Grande Porte,

Brasília: MEC/SEESP, 2005, vol. 5.

BRASIL, Ministério da Educação, Secretaria de Educação Especial. Saberes e práticas da inclusão: recomendações para a construção de escolas inclusivas. 2 ed. Coordenação geral

BRASIL, Ministério da Educação. Secretaria de Educação Especial (SEESP). Política Nacional de Educação Especial na Perspectiva da Educação Inclusiva. Brasília: MEC/SEESP, 2008

BOGDAN, Roberto C.; BIKLEN, Sari Knopp. Investigação Qualitativa em Educação: uma introdução à teoria e aos métodos. Traduzido por Maria João Alvarez, Sara Bahia dos Santos e Telmo Mourinho Baptista. Porto Codex, Portugal: Porto Editora, LDA, 1994.

FAZENDA, Ivani (org). Metodologia da pesquisa educacional. 7. ed. São Paulo: Cortez, 2001.

GIL, Antonio Carlos. Como elaborar projetos de pesquisa. 4. ed. 10. reimpr. São Paulo: Atlas, 2007.

MARCONI, Marina de Andrade; LAKATOS, Eva Maria. Técnicas de pesquisa: planejamento e execução de pesquisas, amostragens e técnicas de pesquisa, elaboração, análise e interpretação de dados. 7. ed. 3. reimpr. São Paulo: Atlas, 2010.

MARCONI, Marina de Andrade; LAKATOS, Eva Maria. Fundamentos de metodologia científica. 6. ed. 7. reimpr. São Paulo: Atlas, 2009.

SEESP/MEC. Brasília: MEC, Secretaria de Educação Especial. 2006. Disponível em http://portal.mec.gov.br/seesp/arquivos/pdf/const_escolasinclusivas.pdf. Acesso em 13 de novembro de 2008. 